\title{
The Communication in the Algerian Company: is a Technical Tool or a Managerial Practice? Case of the Internal Communication in a Financial Company of BADR
}

\author{
http://doi.org/10.21272/fmir.5(1).29-41.2021
}

Gadi Ibtissem, ORCID: https://orcid.org/0000-0002-9713-0359

Lecturer "A”, University ORAN 2, Algeria

Bessaim Radia, ORCID: https://orcid.org/0000-0002-8551-6844

Doctoral Student, University Oran 2, Algeria

\begin{abstract}
The topic was chosen due to the role that communication plays which is growing gradually in all forms of organization. It's a part of strategic perspective and is gained through diverse relational acts that are establishing with external environment and within organization, between the structures, between groups or between individuals, organization needs the internal communication in the situation of organisational change, conflicts, creativity. We are focusing in this study on two sides, the tools established which can improve the internal communication and the top down communication which can create a healthy climate gives a solid foundation upon of transparency and confidence inside furthermore it reflect the good reputation and image of the company outside. The purpose of this article is to determine the technique tools of internal communication which can affects the performance of a financial company: Bank of Agriculture and Rural Development, his contribution to personals, as a reflection tool constituting a certain number of benchmarks permitting them to seize a new approach to the concept of organizational communication. Firstly, we counted on the stages of scientific research by gathering information about the company, after that we chose our sample, we elaborated the questionnaire to answer the questions, Secondly, we analysed the process of internal communication in the bank. Our sample contained 20 employees all of them were competent employees, we found that internal communication is not just a simple operation it consists in disseminating and sharing information, but also it contributes greatly to motivating, instilling and establishing confidence among various members of the organisation, appreciating the efforts. Finally, we have reached that internal communication is a managerial practical which is a source of effectiveness and efficiency than a simple tool.
\end{abstract}

Keywords: communication, internal communication, message, relationship, goals.

JEL Classification: A1, G21, M13, M54, J21.

Cite as: Ibtissem, G., Radia, B. (2021). The Communication in the Algerian Company: is a Technical Tool or a Managerial Practice? Case of the Internal Communication in a Financial Company of BADR. Financial Markets, Institutions and Risks, 5(1), 29-41. http://doi.org/10.21272/fmir.5(1).29-41.2021

Received: 19 January 2021

Accepted: 25 February 2021

Published: 30 March 2021

Copyright: (C) 2021 by the authors. Licensee Sumy State University, Ukraine. This article is an open access article distributed under the terms and conditions of the Creative Commons Attribution (CC BY) license (https://creativecommons.org/licenses/by/4.0/)

\section{Introduction}

Communicate! That's the catch-all term that invades our world since the XXth century. Nothing should be done without using communication. The entire world communicates and very numerous are who talk about the communication, it is increasingly taking a preponderant place in modern managerial literature. The communication is the base of all form of human relationships, through an exchange process where, most of the time, people in relation, are alternately emitters and receivers.

facing technological and economic mutations, the transformations is intervening in all organizational levels and disrupt traditional forms of organization, they are imposing radical changes in attitudes at work, and companies are increasingly engaging in the reorganisation of their activities and the renationalization of their management and this of course cannot be achieved smoothly as soon as it concerns human reports. 
For years, the communication has served as a commercial and political tool. Today, it is resolutely put at the service of the development of nations and takes from this moment an irrevocably human dimension.

Our industrial world is becoming a world of information and communication. The elaboration of communication policies is therefore essential, for the establishment of a coherent and healthy working climate

which contributes to creating positive attitudes towards the company's profitability objectives. Managerial communication is complementary to the actions of internal communication which are aimed directly at all collaborators plays a preponderant role in the functioning of a company and allows to make the link between the different employees. Creating a feeling of belonging to a team and conveying the values of the society are other objectives of internal communication and reinforce its unmissable aspect.

Through the communications policies we essentially seek to reduce conflicts and increase production by improving living conditions at work, which implies the setting up of a device allowing a continuous dialogue. In other words, the quality, the performance and added value for the company pass through communication and it can constitute the lever of this device. From this point of view, the communication appeared to be a factor favouring performance, in particular that of external communication.

Our study aims to situate the position of internal communication in an Algerian financial company the bank "BADR" and its impacts on collaborators.

For that we are going to answer the question: How our modern vision of communication is drawn and what Impacts today on our companies?

For this, we will address a descriptive approach to present the theoretical concepts of this activity and an analytical approach to diagnose the role of communication in this bank.

\section{The Communication in the Company: Definitions of the Concepts}

The communication also interests all scientific disciplines, which as Lucien SFEZ (2010) points out, each have their own acceptance: thus, in linguistics communication is above all language.

According to the definition of the social psychology of G. Bateson ${ }^{1}$ : «the communication is the study of the reactions of individuals to the reactions of other individuals. We must examine not only the reaction of $A$ to the behaviour of $\mathrm{B}$, but also how these reactions affect the conduct of $\mathrm{B}$ and effect of the latter on $\mathrm{A} »$.

The communication is a condition « sine qua non » of human life and social order.

Man does not constitute an isolated being but a social being, socialist, socialized; its relationships are determined by the interactions and intercommunications with others.

Roger Mucchielli (2014) shows that the interhuman relationship; the place itself far from being a product or an effect of communication is the ground on which it develops.

If we now had to start from the definition of the company, we would say that it is certainly an economic entity that produces goods or services, but it is also and above all a system in relation to other systems.

It is also a social organization, a kind of complex and dynamic reality in which several dimensions overlaps, economic, technological, structural, which in turn generate human scale functioning of the organization where the psychological, sociological, and cultural dimensions intervene.

In this multidimensional gear intervenes communication between the members of the organization and of course, its quality depends on the organization of the coherence of all these parameters.

1.1. Evolution of the concept of communication. The term of communication is broad. Diderot ${ }^{2}$, in 1753 already wrote in Encyclopedia with word Communication: « Communication: this term has a large number of meanings ».

\footnotetext{
${ }^{1}$ Gregory Bateson is an anthropologist which belongs to one of the great contemporary scientific dynasties. Influenced by cybernetics, the group theory and that of logical types, he was very interested in communication (human and animal), but also at the foundations of knowledge of human phenomena. He is at the origin of the school of Palo Alto.

2 Diderot, writer, philosopher and French encyclopedist of lights.
} 
At the end of the XXth century, communicating begins to mean also transmitting, definition close to all current senses of communication; it is at the same time the act, the object and the means of the pooling, or the transmission of message.

Communication therefore seems to correspond to a central concept of the life of societies and organizations. In the original sense, the term communication means « participating in», and approaches the Latin «communicare »: to share, to be in relation.

Generally, communication is a process of exchanging information between two or more people (Stéphane OLIVESI,2005).

Through this definition, the opportunity is giving to us to clearly distinguish the meaning of the two concepts « communication » and « of information », where communication takes place as the actual exchange process, while the information intervenes as « its ingredient, its raw material, its element», and of course, the quality of the latter and the way in which it is disseminated depends on the quality of the communication.

We can illustrate the elements characterizing the field of communication in the company in four points:

Descending, ascending information (flow).

The manual or computerized information system.

The internal communication (environment).

The informal exchanges.

In a broader perspective, we will remember that « the communication designates all the actions undertaken to put people in relation with each other in the realization of a common project » (F. Charvin, J.P. Marhuenda 1992).

According to the works of SHANNON ${ }^{3}$ on the information and its circulation in the field of information many approaches have developed, the term of information is very meaningful. In the IT field, it designates technical data, in the written or spoken press, it refers to journalists' news.

In the current language, it can denote the knowing and knowledge.

In company, a service note, a slip, a statement of statistics..., can constitute information, it considered as the vector of interpersonal exchanges.

Table 1. Basic diagram: elements constituting the field of the communication

\begin{tabular}{|l|l|}
\hline$\underline{\text { Sender }}$ & $\begin{array}{l}\text { It constitutes the subject itself; it is from him that the message leaves. The receiver is the subject } \\
\text { who receives the message }\end{array}$ \\
\hline$\underline{\text { Receiver }}$ & $\begin{array}{l}\text { It is about the nature of the information even object of the transmission, the content of the } \\
\text { message }\end{array}$ \\
\hline$\underline{\text { Message }}$ & $\begin{array}{l}\text { This is the route or physical system channel that introduces the message or information that is } \\
\text { object of the exchange. }\end{array}$ \\
\hline$\underline{\text { Channel }}$ & $\begin{array}{l}\text { It constitutes a set of signs specific to each individual which attributes meaning or a sense to the } \\
\text { message }\end{array}$ \\
\hline$\underline{\text { Code (encoding and Decoding) }}$ & It is the deposit in which the individual draws his code to deliver a message \\
\hline$\underline{\text { The frame of reference }}$ & It is the reaction about information. \\
\hline$\underline{\text { Feed Back }}$ & $\begin{array}{l}\text { These are all disturbances during the transmission of a message, in cybernetics; noises are } \\
\text { technical noises (device failure communication interference). }\end{array}$ \\
\hline
\end{tabular}

Source: J.M. PERETTI (2000).

1.2. The communication models. Since the twentieth century, communication theories have been developed in order to represent schematically information exchanges.

The model of Harold D. Lasswell (1930-1940).

The school of Shannon and the information theory.

WIENNER and the cybernetics.

The model of communication of Jackobson.

\footnotetext{
${ }^{3}$ Claude Elwood Shannon is an American electrical engineer and mathematician. He is one of founding fathers, of information theory.
} 
The school of Palo Alto.

The communication model Communautaire.

\section{A. The model of Harorld D. Lasswell (1930-1940)}

Lasswell is interested in mass communication. According to this theorist, a communication action can be properly described by answering the following questions:

Who? This is here the sender of the message. As part of a communication project, it is probably the announcer.

Says What? The model of Lasswell takes into account the content of the message, namely the information to be transmitted to the target.

How? Or in Which Channel? Lasswell wonders at this level about the medium or the media used to get the message across.

To Whom? This is here the message receiver, more commonly called, in communication strategy, the target.

Whith What Effect? the theorist pushes the reflection on the consequences of the message on the receiver, that is to say the conative aspect on the target : act of purchase, membership

The model of Harold D. Lasswell is used in constructions of communication messages such as a commercial letters and prospecting couriers. This theory materializes the information (message) as a process led to influence it and persuade the receiver. It can be used under same conditions as the method of AIDA ${ }^{4}$.

\section{B. The school of Shannon (1949)}

This model has the name of an engineer (Shannon) engineer at the bell, who had worked on the transmission of the electrical signal on telephone lines and the philosopher (Weaver) which applied to broaden this theory to human communication. These two characters materialized the first communication diagram. The model of Shannon and Weaver has been develop to respond to the problems encountered in the telegraphic transmissions.

In works of SHANON are very specific and technically oriented. It should be emphasized that are the basic diagram of communication system has prevailed in most analyzes of information and its circulation. The sender must transmit a message to the receiver via a signal. The difficulty resides in the faithful restitution of the message, knowing that parasitic factors are likely to parasitize the transmission.

This approach «physical » of the information system highlights at this stage the disturbing factors of the transmission. However, this simplistic diagram finds its limits. It cannot apply to all communication situations. Indeed, the existence of several receptors is not envisaged. It abandons the psychological and sociological elements that can influence the understanding of the message.

We note in the frame that the author shows that the communication takes the meaning of INFORMATIONS $=$ CIRCULATION.

For Shannon, the information is not the object of the transmission; this is an abstract statistical greatness qualifying the message regardless of its meaning.

\section{Wiener and the cybernetic ${ }^{5}$ (1948)}

This school is more a way of thinking than detailed theory

Bearing the idea of feedback, it makes the technical and linear conception of the circulation of information obsolete.

This model incorporates the notion of feedback. This notion can be defined as the reaction of the receiver to the message sent by the sender. This theory allows to project into a bidirectional information system:

$>$ From the sender to receiver;

\footnotetext{
${ }^{4}$ The model A.I.D.A. was formulated in 1898 by St Elmo Lewis, a precursor of sales by correspondence, (Attention; Interest; Desire; money); this is the rule that must be followed to lead a prospect towards the realization of his act of purchase.

${ }^{5}$ Norbert Wiener (Born November 26, 1894 in Columbia (Missouri), United States, died March 18, 1964 in Stockholm, Sweden) is an American mathematician, theorist and researcher in applied mathematics, best known as the founding father of cybernetics.
} 
From receiver to sender.

This model differs both previous, which integrate a unidirectional vision. We conceptualize thus the exchange of informations in a circular approach. Wiener paves the way for more complex communication diagrams.

In the diagram of Wiener, we distinguish 2 types of feedback:

$>$ The positive feedback: accentuates a phenomenon with a snowball effect.

$>$ the negative feedback: maintaining a relationship in a state of balance between the actors in a phenomenon of regulation.

This school brings a plus in the analysis of human interactions, because it allows us to study the influence of the communication on the receiver and its impact in the action.

D. The model of communication of JACKOBSON (1973)

This model revolves around verbal messages. It makes to appear 6 main functions: conative, phatic, metalinguistic, referential, poetic, and expressive.

1-Conative function: its goal is to make the recipient act (receiver). In a communication campaign, the conative objective is to buy a given product.

2-Phatic function: its goal is to maintain contact. In a communication campaign, it is akin to a visual reaction to the use of garish colours, of shocking visuals elements or strong messages.

3-metalinguistic function: its goal is to explain one language by another language. In a communication campaign, we attribute it to the translation into French of a slogan in English for example.

4-Referential function: its goal is to direct the message towards referents such as people, objects, habits... it understands the information conveyed by the message. In a communication campaign, it is used in the context of a statement of situation or of a testimony.

5-Poetic function: its goal is to bring an expressive character in order to transmit an emotion in the message. In a TV spot, the vocabulary style and expressions used by the character to convey the message are part of the poetic function.

6-Expressive function: its goal is to transmit to the receiver feelings and personality criteria of the sender. These elements can for example be found in the intensity of the character's voice in a radio spot.

According to Jacobson, the 6 functions of language « are not mutually exclusive to each other, but often overlap ». These functions are therefore cumulative in the use of the diagram of Jacobson.

\section{E. The Invisible College of Palo-Alto (1984)}

Among analysts and researchers belonging to this school, we note: G. Batesonn, R. Birdwhistell, D. Jakson, have attempted to resume the study of the phenomenon of the interpersonal communication without going through the linear or technical models.

According to, this theory he approaches of Shannon must be rejected in social science, because it has been designed by and for telecommunications engineers.

This theory throws the foundations for understanding the information process. The communication context is, according to these researchers, essential to understanding the message. It uses the theory of systems, which allows him to intervene in the analysis of the phenomena of communication the part of what goes to the individual and the part of what comes from the environment system.

There is to here to emphasize that this theory is interested in the analysis of the interrelational mechanisms linking human systems. The human systems are considered opens, in interaction (interdependent with the micro and macro environment).

\section{F. The Model of Community Communication (2007)}

When the first social networks appeared on the internet, the agencies and other communication professionals have not grasped the importance of these new information relays. For a while the messages of the communication campaigns did not reach their targets. This is explained by a virtual barrier (filter) set up by the social network community. 
It wasn't until 2007, that a community communication model appeared. Although simple in its schematic representation, the model is developed by an operational communication professional: Julien Pansier ${ }^{6}$. After several months of investigation (research, interview, investigation), throws the foundations for understanding its new communication targets.

This model takes into consideration the emergence of physical and virtual communities in $20^{\text {th }}$ century society. This modern theory puts forward the fact that the message is filtered by the codes. The mores and means of communication called «communals».

The receiver within a group claiming any membership will be affected by the message after it has passed through the community's communication channels. This diagram can be easily transposed on social networks. A message broadcast by a sender will be read, apprehended, interpreted and very often transcribed differently. This constitutes the basis of internet buzz.

Message observation:

From the point of view of the sender: the message is sent to the receiver but is encoded by the communication channels of the community. The information received by the receiver may be different (than the one originally sent) and misinterpreted.

From the point of view of the receiver: the feedback is no more controlled, since it transits through the community filter.

\section{The Importance and the Role of the Internal Communication}

We cannot communicate well externally if we do not communicate well internally. The internal communication and one of the declinations of corporate communication. It is the component of a global system of organization of flows and exchanges.

Several researches have shown that large organizations seem to give a place to communication in their organizational structures. The communication in the organization takes a decisive place. "the internal communication, it is the set of principles et practices that allow the exchanges of messages, ideas and a value between the members of the same organization $»^{7}$.

In successful companies, people communicate with each other. And beyond communication, they act not only according to their missions but also according to their contribution. They try to evolve together because the company is not a stack but a network of competence. The internal communication has this role: develop the collective sense. If the communication has no human aim, it is useless. If the communicator has no an ethic, he becomes a tool of the economic propaganda.

The most managers spend their times communicating with their employees, this is also valid for employees who seek to obtain information. The communication is an essential tool.

The overall objective of internal communication consists to harvest and then diffuse, to communicate, information to allow the company and its internal actors to exist. This information may have for origin the rumour. The need for information considers the different events that unfold over time. It varies according to the places and the contexts; all the services do not have the same demands. It is different depending on the targets which may be numerous.

2.1. The internal communication supports in the company. It is about to put forward the communication and information devices in a company whatever its activities. Some companies use the means to allow a good circulation of information.

The implementation of communication covers four main objectives:

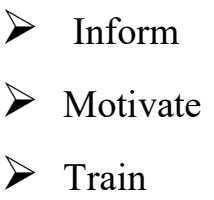

${ }^{6}$ Trainer and Author in Communication. Avignon, France.

${ }^{7}$ Christian Michon, Doctor of economics and companies' administration, author and professor at the Superior school of Commerce of Paris. 
Build the image or ethic of the company.

\section{The communication fulfills eight main objectives compared to change:}

Make the vision known to all the employees concerned;

Inform about the unfolding of the change;

reassure on the merits of change and its management;

$>$ facilitate the evolution of individuals by showing the diversity of representations;

$>$ valorise the efforts made by the actors to concretize the change;

$>$ help resolve difficulties encountered more quickly;

$>$ broadcast new behaviours that already support change;

Reassure the parties concerned situated outside of the company.

We can say, that the valorisation of individual or group efforts sometimes even modest, is the other determining objective of the communication because it holds an important place in the dynamic of change.

\subsection{The role of the internal communication}

A Long-Term Investment for the Company: It is more precisely an approach which consists of starting from the internal, by creating a culture and a company spirit to head towards the external.

The sale force of a company certainly depends on the technical means developed to promote a product or a service but also and especially of the motivation of its employees to want to adhere to all the changes that concern it.

A Global Strategy: A global strategy in which there is interdependence between all the acts of communication all aimed at building a solid image of the company.

The employees constitute today actors in the company. It is no longer possible to mobilize them without keeping them informed of economic objectives, financial, social, political, ethical and cultural. Projects approaches that many companies have started allowing them to gather all the partners, including those who did not necessarily work together. Communication officers participate in the implementation of projects. And if they do not participate, they must do everything possible to know the origins of the strategy, the events that modify it, the socio-cultural context, Etc. Without this, the risk is great of communicating only purposes when the transmission of the meaning of the project is essential. We cannot appropriate what we do not understand. The project approach is therefore already an act of communication and the internal communication has in charge of manufacturing the media and finding the relevant Medias to convey the strategy.

A Working Methods: A procedures, analysis documents, dashboard, newspaper, review, audio-visual, postings, suggestion boxes.

Reunions, periodic meetings.

It is also and especially attitudes favouring exchange, reciprocity, acceptance of differences, in a word the collaboration.

A Budget Even More an Investment: it is generally a report to be established between the turnover and the amount necessary for a communication policy (1\% to $2 \%$ in general). Finally remember that the main element of a good communication policy is the most objective recent information possible, to avoid any form of rumour or misinterpretation and to ensure the credibility of the hierarchy and the adhesion of all members of the organization to everything concerning their company.

A added value of the company: The internal communication brings added value to management. This depends on the management style that we adopt. Taylorian organizations like pyramid organizations are not frankly concerned by communication problems. We could go so far as to say that they are content to inform being situated in the strict diagram of communication where there is a sender who sends a message and a receiver who receives (or not) a message. Communication is instinctive and preoccupies little about the impact.

Cellular or network organizations have a whole vision of communication since it is a question of relationship, of dialogue and listening: to deepen this point, checks out the men are not phones page. Knowing how to 
inform and knowing how to communicate are competences that managers must possess. For this they need to be helped in their roles as communicators both from a logistical and organizational point of view. In these complex organizations where the hierarchical line is reduced. The internal communications also function as a communication resource center, centralizes media, establishes graphic and editorial charters, decompartmentalize services and sectors of activity, and facilitates transfers of experience.

A Managerial Practice: The internal communication covers all the services that is can provide particularly as a motivational tool for employees whatever the size of the company. As an indispensible managerial tool, the internal communication must obey a communication plan in which information is constructed and whose the different medias are written (display or newspaper of company), the oral (seminar or conference of company), the audio-visual (video or CD-ROM), the electronic communication (intranet, extranet, newsletter). The internal communication fulfils multiple functions:

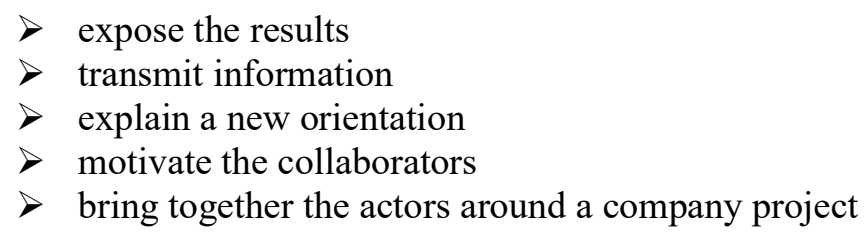

Thus, an internal communication strategy makes it possible to bring together managers and employees for better bilateral listening and to meet the expectations of employees in terms of information.

A tool to animate and mutualise. The internal communication jointly fixes a language, a culture, and the values. Corporate culture is a notion that appeared in the $80 \mathrm{~s}$, it comes at a time when the classic model of the family company has less and less going. It is then a question of finding another relation of belonging to the company since the relationship to family/chef of company is obsolete. Family or corporate culture, it is very important for employees to have reference points in terms of image. This reflection around the creation of an identity specific to the company can be pushed even further and we can imagine that each service also disposes its own culture. This corporate culture is of course aroused by the history of the company, by the men who make the company, from employees to executives, by events.

\subsection{The internal communication supports in the company}

It is about putting forward the devices of communication and information in a company whatever its activities.

Some companies use means to allow a good circulation of information.

The internal communication must fulfil two symmetrical missions to listen, to inform, and a third more subtle, to compose. For this large companies do not hesitate to put in place a certain number of means:

1. To listen: it is in this sprit companies have multiplied, the information relays.

2. To Inform: to set up real internal communication strategies, companies dispose techniques of transmission.

3. To Composer: the internal communication must overcome several difficulties:

4. Avoid the mismatch between what employees live and think about their company.

5. Speak with one voice to the different internal audiences with clear messages.

6. Harmonize internal and external communications that is to say no external action can do without an internal pane.

7. The Negotiation is done with those who have the solution, must be quality to avoid wasting time and to arrive more quickly to solutions.

The oral means: the oral is the oldest tool in internal communication. It is currently undergoing a profound renewal which makes it appear to be the most affective of the means available.

If the written procures the information, oral provides the meaning through dialogue and exchange.

Thus, the entire internal communication policy is essentially based on the animation efforts of the hierarchy and goes beyond the strict framework of formal reports. 
The employees at all levels of an organization continually seek information that informs them not only about their direct activity but also on the future of their job, of their company, on the changes that concern it...

They also seek contacts, exchanges with their peers but also and especially with their superiors in a search for consideration of recognition and enhancement of their competence. Hierarchical animation constitutes thus more than one activity it must translate into managers at all levels by attitudes of proximity and availability. It aims to structure the reports through which the activity of employees is exercised, in their direct relations with the collaborators.

It encompasses information, meeting and dialogue mechanisms. The brand image of the company is capable of arousing pride of belonging for all the personal.

In this case, the image must correspond to the idea that the personal of the company have. The good internal communication will therefore depend on a perfect collaboration and coordination of all the actors together.

The objective being to build an image of the company by motivating its personal.

\section{Presentation of the study and of sample}

The object of our approach consists of analyze the role of the internal communication, to constate its impact on performance within the banking agency of the BADR, we have determined the main axes of this activity to build our questionnaire.

The choice of sample carries 20 employees. It turns out that $30 \%$ of them have experience between $05 / 10$ years, between 1-10 years and over of 20 years respectively and the experience of $20 \%$ which remains between $10-20$ years. Knowing that $55 \%$ of the sample are senior executives and $65 \%$ have a university level, this help us to properly diagnose the situation of the company well by testimonies based on competent employees.

\section{The study results}

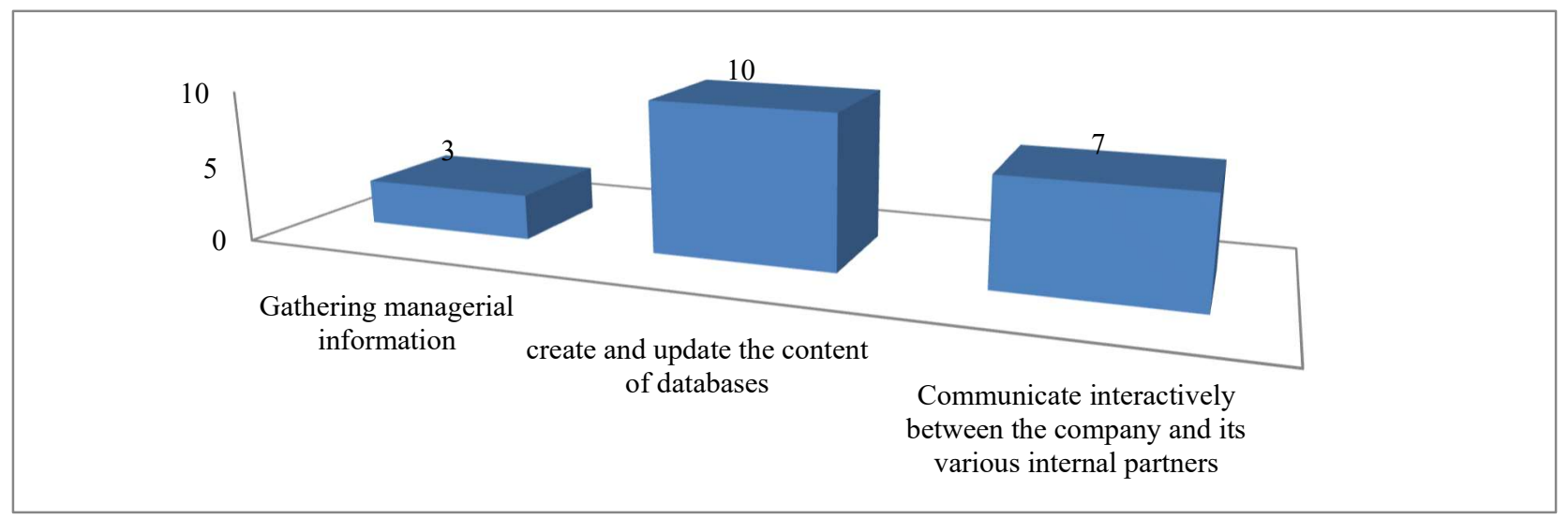

Figure 1. The objectives of internal communication

Source: elaborated by authors from the data collected.

The internal communication at the level of the BADR aims to a priori to enrich the database, including the necessity to meet the needs of clients who are progressing particularly at agency level which dispose an information system using software shared between the different agencies.

The communication with other partners has an important place in communication policy, $40 \%$ of employees questioned indicate that this policy is oriented towards this aspect. While only $20 \%$ estimate that communication aims to collect managerial information, this managerial rate can be explained by the size of this agency in terms of human resources, whose information can be easily shared. 


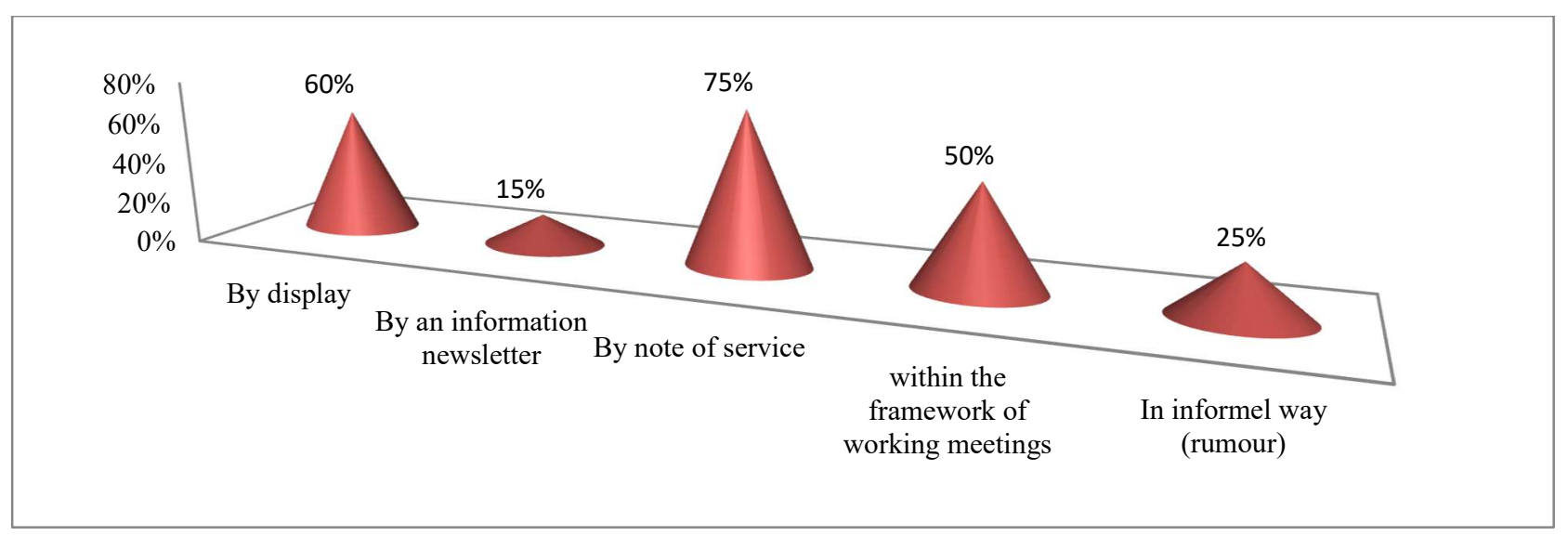

Figure 2. The information sources

Source: elaborated by us from the data collected.

Most employees are informed through formal channels in the occurrence of note of service, a display and during work meeting, $75 \%, 60 \%$ and $50 \%$ respectively.

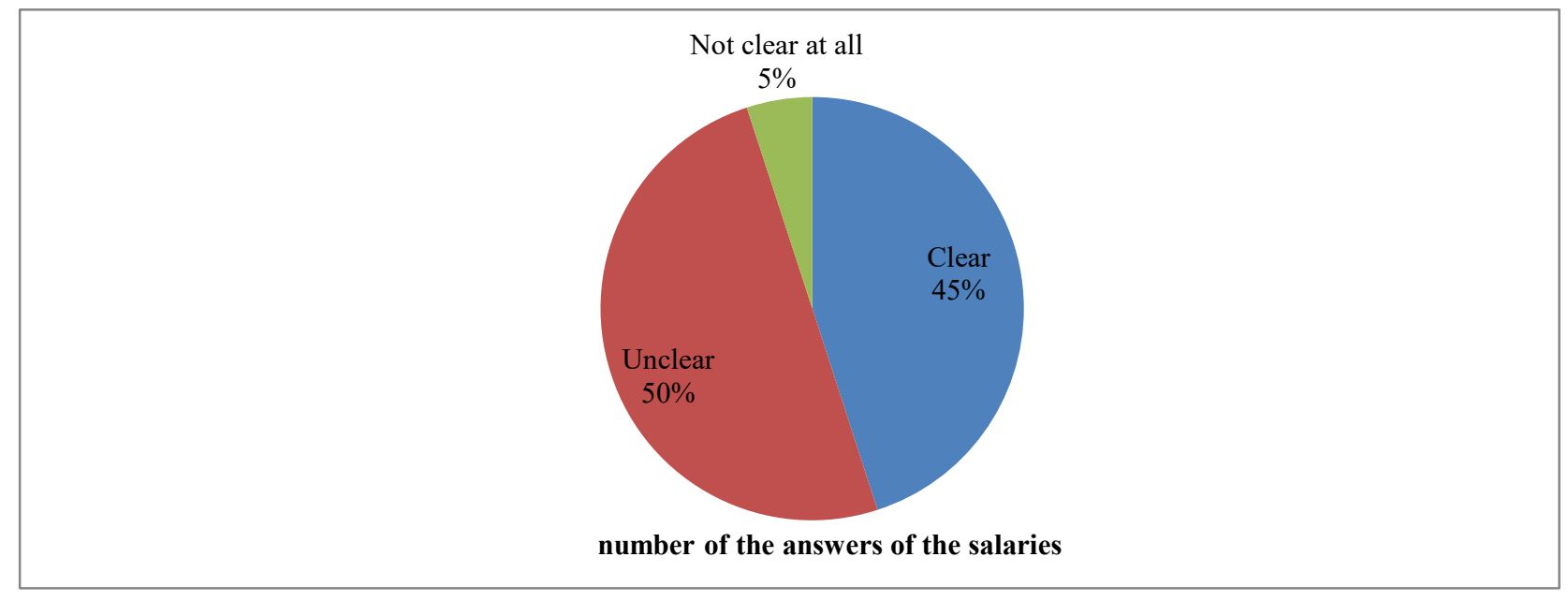

Figure 3. The quality of the information broadcasts

Source: elaborated by authors from the data collected.

$50 \%$ of the employees questioned estimate that the information disseminated is not clear, this indicates the need to take complementary information measures considering the specificities of each member and their hierarchy in the organization.

Table 1 . The objectives of the strategy

\begin{tabular}{|l|c|}
\hline \multicolumn{1}{|c|}{ The objectives of an internal communication strategy in your company } & Rate \\
\hline Decentralization of tasks & $70 \%$ \\
\hline Flexible organizational structure & $30 \%$ \\
\hline Development of Human relations & $45 \%$ \\
\hline Personal contribution to the decision-making process & $50 \%$ \\
\hline Improvement the efficiency of access to the information & $75 \%$ \\
\hline Improvement the competency of actors & $40 \%$ \\
\hline Improvement in the degree of motivation and implication of the actors & $60 \%$ \\
\hline
\end{tabular}

Source: elaborated by authors from the data collected.

The objectives of the strategy of the bank it diversify between the improvement of the efficiency of access to the information according to $75 \%$ of responses of employees, the decentralization of tasks to $70 \%$, improvement in degree of motivation and involvement $60 \%$, and the contribution of personal in the decisionmaking process $50 \%$. The other factors deemed interesting in this strategy occupy marginal places in the occurrence of development human relations and a flexible organizational structure, in this context, the bank will have long term organizational problems. 


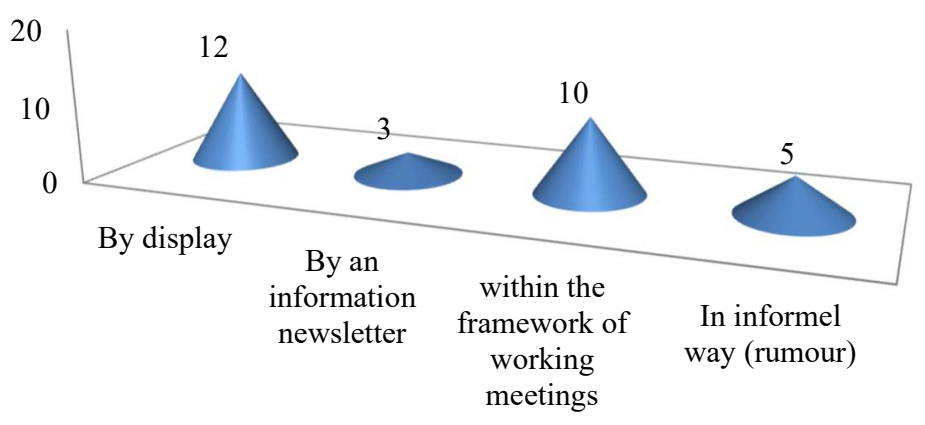

Figure 4. How to be generally informed?

Source: elaborated by us from the data collected.

The classic formal paths are often used to inform the members, in particular by posting, but we signal the low use of virtual communications techniques, and this is due according to the size of the workforce which is not large enough.

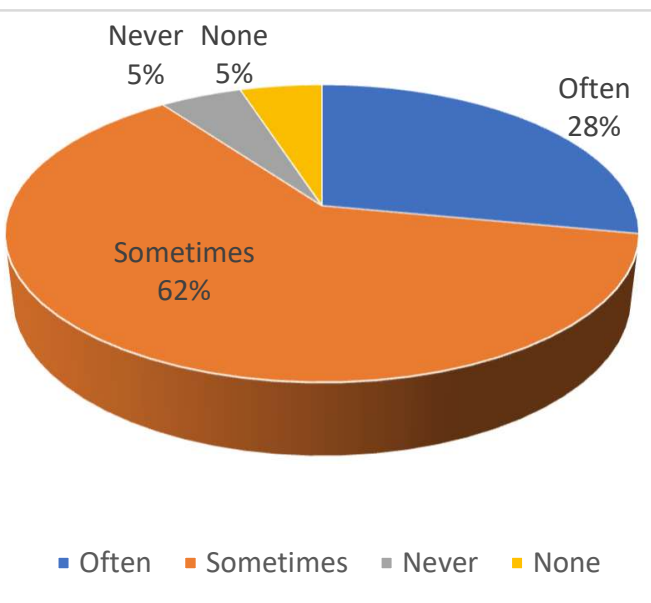

Figure 5. How to be generally informed?

Source: elaborated by authors from the data collected.

$62 \%$ of employees estimate that their preoccupations are not permanently taken into account by their responsibles, this translate the Taylorian form of organization adopted by this bank.

Table 2. The sources of the information according to category

\begin{tabular}{|l|l|l|l|}
\hline $\begin{array}{l}\text { By what are you informed of the following aspects of the life of your } \\
\text { company? }\end{array}$ & Colleagues & Syndicate & Direction \\
\hline The nature and the number of clients & $25 \%$ & $5 \%$ & $70 \%$ \\
\hline The Development projects & $15 \%$ & $10 \%$ & $75 \%$ \\
\hline The rights and duties of employees & $15 \%$ & $55 \%$ & $30 \%$ \\
\hline The informations on personal training & $0 \%$ & $0 \%$ & $100 \%$ \\
\hline
\end{tabular}

Source: elaborated by authors from the data collected.

In certain aspects the bank associates the syndicate in projects which concern the development, in addition to its role classic of informing the collaborators about their duties and obligations. On the other hand, the information relating to training are communicated only by the direction.

\section{Conclusion}

We are coming to develop the importance of internal communication in the organization through our practical study in a financial company, the bank BADR, not only in its role of disseminating management information 
but also and especially in its role of mobilization and motivation of the men who compose the organization , a managerial practice which is a source of efficiency and of meaning at work rather than a simple technical tool.

The result of the study shows that the communication in the Algerian company is still in the reconstruction phase and still looking for its place in the general strategy, especially in the small organizations where the managers accord importance to external communication to the detriment of internal, although it is important but nevertheless do not start by improving inside to have the means to communicate outside, where to move towards a more developed and effective practice that of outsourcing (the delegation, the controlled functioning...) of all or part of a marketing service and/or communication...We have that today, what characterizes the dynamics of organizations is continuous and unpredictable change and the need to adapt to it.

The means to achieve this consist in the elaboration of policies and strategies applied to each of the organization's functions among which communication occupies a most strategic position. In its overall objective, the communication policy aims to position the company compared to its environment, give it a recognizable personality for all its "publics», a distinct identity. To succeed in this approach, it is important that communication in turn recognizes its different publics, both internal and external and addresses them in the language that best touches each of their expectations. It is about in this context to act essentially on the relevance of the objective, on the quality of messages, to target each of the interlocutors, and adapt the appropriate technique to it. In this logic the information intervenes as one of the most important parameters of communication, it imposes to be objective, current and rigorous to offer all the credibility required to ensure the adhesion of its internal public (the employees of the company) and the loyalty of its external public, (the clients, suppliers and others company partners).

But once again, there is place to insist on the capital importance of internal communication, because by its position upstream of the process, it strongly conditions the external image of the company and that whatever technical means that we have put to build it.

We will remember in any case, that effective communication is based more on behaviour than on supports and therefore more on the quality of management, of specific managerial competencies, this ability to situate and to situate its collaborators in the time and the space: short term, medium term, long term, locally as well as globally, than on simple technical tools.

Author Contributions: conceptualization, Ibtissem, G., Radia, B.; methodology, Ibtissem, G., Radia, B.; validation, Ibtissem, G., Radia, B.; formal analysis, Ibtissem, G., Radia, B.; investigation, Ibtissem, G., Radia, B.; resources, Ibtissem, G., Radia, B.; data curation, Ibtissem, G., Radia, B.; writing - original draft preparation, Ibtissem, G., Radia, B.; writing - review and editing, Ibtissem, G., Radia, B.; visualization, Ibtissem, G., Radia, B.; Ibtissem, G., Radia, B.

\section{References}

1. Chalvin, D. (1984). Analyse transactionnel et relation de travail [Transactional analysis and employment relationship]. Edition ESF, Paris. Retrieved from: https://www.memoireonline.com/09/18/10267/m Comment -1-entreprise-peut-elle-renforcer-la-cohesion-d-equipe19.html

2. Chalvin, D. (1995). Les nouveaux outils de l'analyse transactionnelle, pour développer l'énergie des individus et des organisations [The new tools of transactional analysis, to develop the energy of individuals and organizations]. Edition ESF Paris. Retrieved from: http://e82355b94844359339a68872363d 5472.unafe.org.br/

3. Chalvin, D., Joseph, M. (1986). Analyse transactionnelle et vie familiale. [Transactional analysis and family life]. Edition ESF, Paris 1986. http://excerpts.numilog.com/books/9782710105701.pdf

4. Charvin, F., Marhuenda, J.P. (1992). Communication et entreprises [Communication and companies]. Retrieved from: https://www.sudoc.fr/002120720

5. Cordon, A., Mermet, L. (1982). Vocabulaire de l'analyse transactionnelle. Les éditions d'organisation. [Vocabulary of transactional analysis. Organization editions], Paris. Retrieved from: http://www.sudoc.abes.fr/cbs/xslt//DB=2.1/SET=1/TTL=1/CLK?IKT=1016\&TRM

$=$ Vocabulaire $+\mathrm{de}+1 \% 27$ analyse + transactionnelle 
6. D'humieres, P. (1994). Management de la communication d entreprise [Management of corporate communication], 330. Retrieved from: https://www.worldcat.org/title/management-de-la-communicationdentreprise/oclc/468674193? referer $=$ di\&h $\mathrm{t}=$ edition

7. Detrie, P., Broyez, C. (2001). La communication interne au service du management. [Internal communication in the service of management], 238. Retrieved from: https://www. eyrolles.com/Entreprise/Livre/la-communication-interne-au-service-du-management-9782878803662/

8. Donohue, W. A. (2020, 06 01). Differences between formal and informal communication channels. Journal of business communication, 114. Retrieved from: https://www.semanticscholar.org/author/W.Donohue/14050251

9. Fournier, J. Y. (1994). Gérer les rapports de forces, par l'analyse transactionnelle. Les éditions d'organisation. [Manage the balance of power, through transactional analysis. Organization editions], Paris. Retrieved from: https://www.eyrolles.com/Entreprise/Livre/gerer-les-rapports-de-force-par-l-analysetransactionnelle-9782708115712/

10. Genain, L., Lerond, M. (1995). Pratique De L'analyse Transactionnelle. Edition Devicchi. [Practice of Transactional Analysis. Devicchi Edition], Paris. Retrieved from: https://gallica.bnf.fr/ark:/ 12148/bpt6k3333772z.texteImage

11. Hamylton, C., \& Kroll, T. L. (2016). Communicating For Results. (L. O. Number, Éd.) Usa: Student Edition. Retrieved from: https://www.worldcat.org/title/communicating-for-results-a-guide-for-business-andthe-professions/oclc/914290572

12. Lucien, S. (2010). la communication. (q. s.-j. collection, Éd.) Discipline: sociologie et sciences de L'education.

13. Mucchielli, A. (1993). La communication interne et ménagement de crise. [Internal communication and crisis management], 204. Retrieved from: https://journals.openedition.org/communicationorganisation/ 1722

14. Mucchielli, R. (2014). Communications et réseaux de communication - pour accroître l'efficacité dans l'entreprise ", ESF Editeur. [Communications and communication networks - to increase efficiency in the company", ESF Editeur]. Retrieved from:https://www.eyrolles.com/Loisirs/Livre/communications-etreseaux-de-communication-9782710113003/

15. Olivesi, S. (2005). La communication selon Bourdieu. Jeu social et enjeux de société. [Communication according to Bourdieu. Social game and social issues], Paris, L'Harmattan, Coll. Retrieved from: https://journals.openedition.org/communication/519

16. Peretti, J.-M. (2000). Gestion des ressources humaines.[ Human Resource Management]. Retrieved from: https://www.decitre.fr/livres/gestion-des-ressources-humaines-9782711777570.html

17. Roger, M. (2014). Communication et réseaux de communication pour accoitre l'efficacité dans l'entreprise. ESF Editeur [Communication and communication networks to increase efficiency in the company. ESF Publisher]. Retrieved from: https://www.ascodocpsy.org/santepsy/index.php?lvl=author see\&id $=5259 \&$ page $=1 \&$ nbr_lignes $=193 \& 1$ typdoc $=a \% 2$ Co\&nb_per_page custom $=100$

18. Sfez, L. (2010). La communication. Discipline: Sociologie et Sciences de l'éducation. [Communication, Collection. Discipline: Sociology and Educational Sciences]. Retrieved from: https://www.puf.com/content/La_communication

19. Stéphane, O. (2005). La communication selon bourdieu. jeu social et enjeux de société. Paris: l'harmattan, coll communication et civilisation [Communication according to bourdieu. Social game and social issues. Paris: the harmattan, communication and civilization coll.] Retrieved from: https://www. worldcat.org/title/communication-selon-bourdieu-jeu-social-et-enjeu-de-societe/oclc/424306259

20. Tani, M. E. (2019, 01 30). Epistemologie of Information and Communication Sciences. Image and Communication, 128-141. Retrieved from: https://www.asjp.cerist.dz/en/article/75914

21. Westphalem, M. H. (2001). Communication: le guide de la communication d'entreprise (3eme édition). [Communication: the guide to corporate communication (3rd edition)], Dunod, Paris, 417. Retrieved from: https://halldulivre.com/livre/9782100040810-communicator-le-guide-de-la-communication-d-entreprise-3eedition-marie-helene-westphalen/ 